\title{
Effects of Chlorhexidine Solution Formula on Oral Health Status and Occurrence of Ventilator -Associated Pneumonia among Intubated Intensive Care Unit Patients
}

\author{
Hanan Mohammed Mohammed ${ }^{1}$, Anwar Sabir Gamal ${ }^{2}$ \\ ${ }^{1}$ Assistant Professor of Medical-Surgical Nursing Department, Faculty of Nursing, Ain Shams University, Egypt \\ ${ }^{2}$ Department of Anesthesia and Intensive Care - Faculty of Medicine - Ain Shams University, Egypt
}

\begin{abstract}
Ventilator-associated pneumonia is the foremost validation for incessant oral cleanliness. The most important strategy for reducing VAP is improving oral hygiene. The present study aimed to examine the effect of chlorhexidine solution formula on oral health status and occurrence of ventilator - associated pneumonia among intubated intensive care unit patients.

Study design: A quasi-experimental design was utilized.

Study sitting: The study was conducted at chest intensive care Unit at Ain Shams University Hospital.

Study sample: The convenience sample of 50 patients were randomly and alternatively divided into two equal groups (study\& control), 25 subjects each.

Tool of data collection: Demographic and clinical data Sheet, Beck oral health assessment scale and Modified clinical pulmonary infection sheet score were used.

Results: the findings of this study revealed that concerning comparison of oral health status changes between the study and control groups throughout study period, it could be observed that highly significant difference was elicit between the study and control groups on $5^{\text {th }}$ day. The incidence of VAP is highly statistically significantly among the control group compared to the study group (56\% and $20 \%$ respectively). Also, the study demonstrates that only $28 \%$ of patients in the study group stayed for more than 10 days in the ICU compared with $60 \%$ of patients in the control group.

Conclusion: Chlorhexidine solution formula has an effect on improving oral health status. Moreover, it reduces growth of different bacterial species (Gram negative and positive bacteria) and in turn it has reducing the occurrence of ventilator associated pneumonia and thus, it short the length of stay in ICU which is consider an important determinant for the development of VAP.
\end{abstract}

Recommendations: This study recommended, the use of chlorhexidine solution formula as an oral mouth care for orally intubated patients.

Keywords: Chlorhexidine, Oral health, Ventilator-associated pneumonia.

\section{Introduction}

One of the most important nursing management is to keep oral care and hygiene in critically ill patients. In the ICU, the mouth usually allows entry for life sustaining activities, such as endotracheal intubation for ventilation and orogastric tubes for enteral nutrition. Unfortunately, these intercessions require patients with uphold an open mouth, and impair the natural airway defense's. This defenseless position, in consolidation with different treatments, might help quickly deteriorating oral state and reliance looking into nursing on allay tuberelated discomfort, thirst, oral lesions and the accumulation of saliva, sputum and oral microscopic organisms. In this way, the condition of a patient's mouth can be a record of nursing consideration got ${ }^{(1)}$. Swallowing and salivating mechanisms of a mechanically ventilated patients are weakened because of sedations, muscle relaxants and the presence of an endotracheal tube (ETT); thus, there are a reduced ability to clear the oral cavity of accumulating pathogens. These organisms originate in the oral cavity, have the opportunity of getting transferred to the lungs in that way causing Ventilator Associated Pneumonia (VAP). In compromised patients, an endotracheal tube causing removal of the natural protective barrier for the lungs, consequently bacteria can easily travel from the mouth to the lungs in compromised patients ${ }^{(2)}$.

Ventilator-associated pneumonia (VAP) is defined as nosocomial pneumonia in mechanically ventilated patients which develops more than $48 \mathrm{~h}$ after initiation of mechanical ventilation(MV) ${ }^{(3)}$. VAP arises when there is bacterial invasion of the pulmonary parenchyma in a patient receiving mechanical ventilation. The pathogenesis of ventilator-associated pneumonia usually requires two important processes to take place: bacterial colonization of the aerodigestive tract and the aspiration of contaminated secretions into the lower airway. The diagnosis of VAP is currently the presence of a pulmonary infiltrate on chest radiograph plus two of the following three criteria: leukocytosis or leukopenia, purulent respiratory secretions and fever or hypothermia and the next step is to obtain samples of the lower respiratory tract for microbiological tests ${ }^{(4)}$. Nowadays, 
Ventilator-associated pneumonia (VAP) is the foremost validation for incessant oral cleanliness ${ }^{(5)}$. Expanding worries about the morbidity and mortality associated with nosocomial pneumonia provoked enquiry with attempt on recognize precursors with this often-lethal infection. Evidence approved that insufficient mouth care for intubated patients' may facilitate to the aspiration of bacteria in oropharyngeal secretions, causing VAP ${ }^{(3)}$.

In Egypt, the most recent study that is concerned with an analysis of VAP studies done in Egyptian University Hospitals in the last 10 years revealed that the incidence of VAP ranged from $16 \%$ to $75 \%$, with the lowest ratio in Alexandria and the highest one in Ain Shams University, while the incidence in Mansoura University Hospitals was $22.6 \%{ }^{(4)}$. Comparison with incidence of VAP World Wide, $10-28 \%$ and in the United States 9$27 \%$, it means that incidence of VAP in our ICUs is about 2.5 times more ${ }^{(6)}$.

Oral assessment is an extremely critical in assessing patient's oral status. Such assessment aims to maintain a good standard of oral hygiene, provide evidence to support oral care interventions and has the possibility to reduce the incidence or severity of oral complications ${ }^{(1,3)}$. Oral care is an essential nursing intervention that delivers relief and comfort to patients who are critically ill and cannot perform this simple activity themselves ${ }^{(5)}$. In ICUs, nurses providing oral cares to patients who are uncooperative, have a high-risk procedures and adequate evidence to support these processes are needed. Oral care for intubated patient can be a challenge and at times an impossible task. However, the benefit of oral care outweighs the risk of clear precise oral care ${ }^{(7)}$. The Centers for Disease Control and Prevention (CDC) ${ }^{(8)}$ recommend development and implementation of a comprehensive oral hygiene program, potentially with the inclusion of an antiseptic agent, for settings where patients are at risk for hospital-acquired pneumonia (HAP). In support of this recommendation, researchers have advocated oral hygiene and a subsequent reduction in the colonization of dental plaque as an important strategy in preventing VAP. Despite these recommendations, limited evidence exists to guide nurses' oral hygiene practice in the general ICU population.

The most important strategy for reducing VAP is improving oral hygiene ${ }^{(9)}$. Techniques suggested for removing dental plaques and oral pathogens includes the use of both tooth brush in combination with antiseptic solution as well as cuff pressure control, suctioning and elevation of the head of the bed at 35 to 45 degree. Oral decontamination with antiseptics of adult patients receiving mechanical ventilation is associated with a lower risk of VAP. Chlorhexidine is recommended as the most effective antiplaque agent and has a positively charged molecule, works by binding to negatively charged sites on tooth enamel and mucosal cells. This action results in a reduction of microbial adherence to the tooth and mucosal surfaces ${ }^{(6)}$. Moreover, it has an inhibitory effect against Gram-positive and Gram negative organisms and maintains an antimicrobial activity up to $12 \mathrm{~h}{ }^{(9,10)}$. Several recently published clinical trials of intra-oral disinfection with topical chlorhexidine or povidone-iodine gargle and tooth brushing have demonstrated a reduction in the prevalence of oropharyngeal colonization as well as a reduction in the rate of VAP in mechanically ventilated patients ${ }^{(11-13)}$. Another studies demonstrated that conventional solutions such as Hydrogen Peroxide, ethanol and normal saline are used for mouth care ${ }^{(14,15)}$. Nurses in critical care units are in the ultimate position to provide ideal care for patients ${ }^{(16)}$. If providing creative and systematic oral care can maintain oral health, decrease the incidence of VAP and other outcome measures. The care should be considered an important and critical component of critical care nursing ${ }^{(17)}$.

\subsection{Significance of the study:}

Provision of oral care is far more than a matter of personal grooming. Unclean mouth can lead to serious morbidity and mortality ${ }^{(18)}$. Since mechanically ventilated patients have artificial airway, cannot be fed orally, their secretions decrease, and self-cleaning of the oral cavity is markedly reduced. As a result, oral cavity hygiene worsens and number of bacteria increases excessively, leading to bacterial colonization of the oropharynx and VAP ${ }^{(13)}$. No evidence-based oral decontamination with antiseptics for mechanically ventilated patients has been reported. In addition, the absence of a consistent evidence base method for mouth care leads to difference in the application of mouth care from nurse to another and from one patient to another.Various solutions are used as mouthwash at ICUs. Tape water be plentiful and economical; however, it is a source of nosocomial infections and is therefore not recommended. Normal saline has limited use as a mouth rinse due to its tendency to cause dryness and ineffectiveness in removing debris from the mouth. The use of povidoneiodine as a mouthwash is also not recommended due to its absorption, modifications of the normal flora and microbial resistance it may cause. Sodium bicarbonate solution is a mouthwash that softens the hardened mucosa but causes greater bacterial plaque accumulation compared to chlorhexidine. Chlorhexidine is therefore considered an anti-plaque agent with antimicrobial properties that doesn't lead to bacterial resistance in the oral cavity. Using of chlorhexidine for oral care is considered a low cost, easy-application intervention with a low level of adverse effects. In addition, it is of major importance to prevent oral infections and VAP. The aim of nursing research is to help, develop, create, refine and extend the base of knowledge to the practice of nursing, which is essential for continued improvement in patient care. As a result, the researchers were interested in developing oral care interventions based on chlorhexidine solution formula to maintain oral health status and reduce VAP rate in critically ill patients for fulfilling this principal nursing responsibility. 


\subsection{Aim of the study}

The aim of the study was to examine the effect of chlorhexidine solution formula on oral health status and occurrence of ventilator - associated pneumonia among intubated intensive care unit patients.

\subsection{Research Hypothesis:}

It was hypothesized that the intubated patients who will use chlorhexidine solution formula (study group) will be expected to improve oral health status and reduce occurrence of ventilator -associated pneumonia compared to (control group) patients who will not use this formula.

\section{Subjects And Methods}

\subsection{Research Design}

The research design used is a quasi-experimental, with a study group using chlorhexidine solution formula and a control group not using it.

\subsection{Setting}

The study was conducted at the chest intensive care Unit at Ain Shams University Hospital.

\subsection{Sample}

Fifty adult patients of both sexes with endotracheal tube and mechanical ventilation were eligible for participation in the study. Patients with intubated for at least 48 hours with nasogastric tube, having had no more than one intubation attempt; no facial or oral trauma; no evidence suggesting VAP and had $>20$ teeth of broadly symmetrical (left and right) distribution; and had the ability to maintain a semi-recumbent position, i.e. HOB $30^{\circ}$ were included in the study. Patients were ineligible for study participation if they: had ulceration in oral cavity; required specific oral hygiene procedures in relation to facio-maxillary or dental trauma/surgery; had unstable cervical fracture; received irradiation or chemotherapy on admission to the ICU; had a witnessed aspiration (to eliminate patients with chemical pneumonitis); a confirmed diagnosis of post-obstructive pneumonia (e.g. advanced lung cancer); a known allergy and hypersensitivity to chlorhexidine mouthwash; a diagnosed thrombocytopenia (platelet count less than 40 or other coagulopathy); transfer from another ICU; immunosuppression (either-HIV or drug induced e.g. organ transplant patients or those on long term steroid therapy); or re-admission to the ICU. Also, patients with nasal intubations; tracheostomies; the removal of the tracheal tube for any reason during the study period were excluded from the study.After application of the inclusion and exclusion criteria, the convenience sample of 50 patients were randomly and alternatively divided into two equal groups (study\& control), 25 subjects each. The study group used chlorhexidine solution formula while, the control group received the routine hospital nursing oral care. They were similar in their basic personal characteristics. The mean age of subjects in the study and control groups were $50.1 \pm 5.5$, and $49.4 \pm 5.4$ years, respectively. The study subjects comprised $65 \%$ males, and the control $70 \%$, with no statistically significant differences.

\subsection{Tools}

For the purpose of the study and to collect the necessary data, tools were utilized by the researchers based on the review of the related literature.

Tool (I): Demographic and clinical data Sheet: An assessment sheet was designed by the researchers to collect data regarding to age, sex, history of smoking, date of admission and date of discharge. It also served to record ICU diagnosis, and the mechanical ventilation data related to reasons of intubation and duration on mechanical ventilation. This tool was filled in once by the researchers.

Tool (II): Beck oral health assessment scale: According to Ames et al., $(2011)^{(7)}$, that use of the Beck Scale could standardize oral assessment and guide nurses in providing oral interventions. The scale was developed to assess patient's oral cavity health status and its response to oral care during the study period. It was adopted from Beck, $(1997)^{(19)}$. It includes five categories (lips, gingiva and oral mucosa, tongue, teeth and saliva). The first three categories (lips, gingival and oral mucosa, tongue) had the following scores: (one score) for smooth, pink, moist and intact, (2 scores) for pale, slightly wrinkled, dry, one or more isolated reddened areas, $(3$ scores) for dry and slightly swollen, may had one or two isolated blisters and papillae are red with lesions, (4 scores) for very dry and edematous, entire lip inflamed and generalized blisters or ulceration for each one. The fourth category (teeth) had the following scores: (one score) for clean with no debris, (2 scores) for minimal debris mostly between teeth, ( 3 scores) for moderate debris, (4 scores) for teeth covered with debris. The fifth category (saliva) had the following scores: (one score) for thin, watery plentiful, ( 2 scores) for decrease in amount, (3 scores) for scanty and slightly thicker, (4 scores) for thick and viscid or mucoid.

The five categories scores of the scale are summed to obtain an overall assessment score for oral health status changes as a response to oral care that ranging from 5 to 20 . The total beck oral assessment score was categorized as follows:

- An overall assessment score is 5 means No dysfunction (normal).

- An overall assessment score is 6-10 means Mild dysfunction.

- An overall assessment score ranges from 11-15 means Moderate dysfunction.

- An overall assessment score ranges from 16-20 means Severe dysfunction. 
Tool (III): Modified clinical pulmonary infection sheet score(CPIS): According to Nasiriani et al., (2016) ${ }^{(20)}$ explained that occurrence of VAP was determined by using the (CPIS) and was also used to exclude patients who had pneumonia at the time of admission to the critical care unit. It was developed to serve as a surrogate tool to facilitate the diagnosis of ventilator-associated pneumonia (VAP). It was adopted from The American Thoracic Society and the Infectious Diseases Society of America, (2005) ${ }^{(21)}$. Modified CPIS data and diagnostic criteria was based on 4 clinical assessment, including: body temperature, white blood cell count, tracheal secretions, and infiltrates on chest radiograph. Body temperature had the following scores: (zero score) for value of $36.5-38.4^{\circ} \mathrm{C}$, (one score) for $38.5-39.0^{\circ} \mathrm{C}$ and ( 2 scores) for $\geq 39.1$. White blood cell count $(W B c s), \times 1000 / \mu L$ had the following scores (zero score) for value of 4 to less than 11 , (one score) for 11 to less than 14 , and (2 scores) for $\geq 14$. Tracheal secretions had the following scores: (zero score) for white/clear secretions with negative culture, (one score) for sticky yellow color secretions with (+) positive culture, and (2 scores) for green color secretions with (++) positive culture. Infiltrates on chest radiograph (chest $x$ ray) had the following scores: (zero score) for no infiltrate and clear chest, (one score) for diffuse or patchy infiltrate chest, and ( 2 scores) for localized infiltrate chest.

Points for each variable of the modified CPIS were summed, yielding a total CPIS. The score was varying from 0 to 8 for data analysis. Defining CPIS scores as follows:

- CPIS scores $\geq 6$ defining as a diagnosis of VAP.

- CPIS scores $<6$ defining as an absence of VAP.

2.5. Data collection methods

\subsubsection{Administrative Consideration}

Permission to conduct the study was obtained from the hospital authorities in the chest intensive care unit at Ain Shams University Hospital after explaining the aim and the nature of the study.

\subsubsection{Content and face validity}

The tools were developed after reviewing of related literature and were tested for its content validity by a jury of seven experts in the field (two medical surgical nursing, two critical care nursing educators, one anesthesiologist, one bacteriologist and one statistician). Their opinions were elicited regarding the tools format layout, consistency, and scoring system. and modifications were done to ascertain clarity, relevance, applicability, comprehensiveness, and ease for implementation prior to data collection.

\subsubsection{Ethical considerations and human rights}

Ethical consideration was done through anonymity of the collected data and confidentiality was maintained and the patients are expected to benefit from oral care intervention for either improving oral health status or a method for VAP reduction. In addition, care with unconscious patients was taken because of the risk of chocking by the fluid used. Formal consents were obtained from conscious patients, whereas the consents of unconsciousness patients were obtained from their significant, then, patients were recruited based on the inclusion criteria.

\subsubsection{Pilot study}

Pilot study was conducted on $10 \%$ of study sample (5 patients) who met the predetermined selection criteria. It was carried out to test feasibility and the applicability of the tools and modification was done accordingly and the five patients who shared in the pilot study were not included in the actual study.

\subsubsection{Procedures}

1. Data collection was conducted approximately five months from May to September 2012. Data were collected five days a week twice each day (at 8 AM and 8 PM).

2. An initial assessment was carried out on the first day for all mechanically ventilated patients to confirm that they did not have pneumonia on admission by used the score of modified CPIS $<6$, and free from exclusion criteria. VAP was scored using modified CPIS by the researcher from four commonly used clinical parameters: body temperature, white blood cell count, tracheal secretions, and chest radiographic infiltration.

3. Available patients who fulfilled the studied criteria were randomly assigned into two equal groups. The study group received chlorhexidine solution formula while the control group exposed to routine hospital care without interference from the researchers.

4. Demographic and clinical data Sheet were filled by the researchers, and took about 15 to 30 minutes for each patient.

5. At the first day of the study, baseline oral cavity assessment was done for all patients in the study and control group before providing oral care. The patients' lips, gingiva and oral mucosa, tongue, teeth and saliva were assessed and checked using Beck oral assessment scale. A pen torch was used during oral assessment for more visualization of the oral cavity. Assessment was done twice a day and repeated on day three and then at the end of the study on day five thereafter to determine the changes in the oral health status (duration of the study). 
6. All Patients were seated in semi-recumbent position with the bed head elevated $30^{\circ}$ in order to prevent aspiration of secretions and the development of VAP. Position of the endotracheal tube and cuff pressure was checked before the application of mouth care intervention and adjusted in pressure through a syringe if below the normal levels. This was repeated twice a day. Deep oral suction was provided, as needed, for removing oropharyngeal secretions pooled on top of the cuff of the endotracheal tube.

7. For the study group, chlorhexidine solution formula was prepared by a pharmacist. It was consisted of $3 \mathrm{ml}$ chlorhexidine gluconate $20 \%$ added $200 \mathrm{ml}$ of sterile water; separately $5 \mathrm{ml}$ essence of peppermint was mixed with $5 \mathrm{ml} 95 \%$ ethanol, and then $15 \mathrm{ml}$ glycerin. The solutions were then mixed and brought to $500 \mathrm{ml}$ sterile water. Chlorhexidine is a biguanide antiseptic and disinfectant that is bactericidal or bacteriostatic against a wide range of Gram-positive and Gram-negative bacteria (Lansford et al., 2007) ${ }^{(15)}$. Sterile distilled water is useful for cleaning the teeth, gums and preventing xerostomia so, its recommended mouthwash which is not damaging to the oral mucosa and safe to use (Mori et al., 2006) ${ }^{(16)}$ also use of glycerin mouthwash decreased the sensation of a dry mouth (Chan et al.,2011) ${ }^{(22)}$. This formula provided successful distribution and stability of chlorhexidine gluconate in mouth wash solution (Sharma and Kaur,2012) ${ }^{(23)}$. The formula was packed in an identical container. The pharmacist not involved in the data collection procedures. The application of this formula continued for five days.

8. The technique used for oral care intervention with chlorhexidine solution formula as the following, firstly: prepare the oral environment before formula application by using mechanical cleansing of the teeth, tongue and gums through soft pediatric toothbrush, to prevent mouth injury and decrease bleeding (Fartoukh et al.,2003) ${ }^{(24)}$ which was placed at 45 angles and every tooth was brushed for 5 strokes on lingual, buccal, and biting surfaces. Teeth were brushed for 1 to 2 minutes. The palate and tongue were also brushed. Then the brush dipped in water and put a small amount of toothpaste. The mouth then was rinsed with tap water with an irrigating syringe. It is better to provide systematic oral care using tooth brushing before using chlorhexidine solution (Fathy et al.,2013) ${ }^{(4)}$. Secondly, a suction catheter was used as needed; gently the ventral surface of the tongue and palate was brushed and rinsed. Thirdly, the endotracheal tube was included in the oral care, gently brushed the tube with the toothbrush and gauze to remove debris. Brush teeth at least 1/2 an hour before using chlorhexidine solution. Fourthly, chlorhexidine solution formula was applied to all teeth, the oral soft tissues including buccal mucosa, vestibules, gingiva, and the floor of the mouth and tongue dorsum were swabbed using 4-6 cotton swab. Excess rinse was suctioned out of the patient's mouth after one minute and finally a thin layer of mouth moisturizing gel was applied to all soft surfaces of the oral cavity and lips by using a toothette oral swab. This technique was done twice daily (at 8 $\mathrm{AM}$ and $8 \mathrm{PM}$ ) for five days.

9. The control group received oral care during the routine hospital care once daily during morning shift. After suctioning of oropharyngeal secretions, quickly swabbing of the mouth using normal saline $0.9 \%$ on tongue depressor wrapped in gauze. Mouth gel was applied to lips when available.

10. Axillary's body temperature, sputum color, and WBCs were recorded for all patients in control and study groups at the morning shift, all the study period; from the first day to the fifth day.

11. Chest X-ray was done for all patients in the two groups at the end of the study on day five to observe the shadow of pneumonia. Based on the changes in the result, the degree of chest infiltrates in each patient in the study and control groups was determined.

12. Endotracheal aspirates were collected with a sterile catheter for all patients in the two groups in fifth day of the study. After disconnecting the ventilator, a sterile suction catheter was introduced into the endotracheal tube until $5 \mathrm{~cm}$ protrude beyond the tube and $2 \mathrm{ml}$ of endotracheal aspirates were obtained by suction. The part of the catheter containing the aspirates were cut and placed in sterile test tubes and sent to the laboratory for sputum culture.

\subsubsection{Statistical analysis:}

Data were collected, coded, tabulated, statistically analyzed using an IBM personal computer with Statistical Package of Social Science (SPSS) version 20 where the following statistics were applied. The data were presented in tables and graphs as frequency and percentage.

1. Descriptive statistics: in which quantitative data were presented in the form of mean, standard deviation (SD), range, and qualitative data were presented in the form numbers and percentages.

2. Analytical statistics: used to find out the possible association between two groups. The used tests of significance included:

*Chi-square test $(\chi 2)$ : was used to study association between two qualitative variables.

*Student t-test: is a test of significance used for comparison between two groups having quantitative variables. $\mathrm{P}$ value of $>0.05$ non-significant, $\mathrm{P}$ value of $<0.05$ significant, $\mathrm{P}$ value of $<0.001$ highly significant. 


\section{Results}

Table (1): Clinical data characteristics in the study and control group $(\mathrm{n}=50)$

\begin{tabular}{|c|c|c|c|c|c|c|}
\hline \multirow{3}{*}{$\begin{array}{l}\text { Clinical data } \\
\text { characteristics }\end{array}$} & \multicolumn{4}{|c|}{ Groups } & \multirow[t]{3}{*}{$\mathbf{X}^{2}$} & \multirow{3}{*}{ P-Value } \\
\hline & \multicolumn{2}{|c|}{ Study $(n=25)$} & \multicolumn{2}{|c|}{ Control(n=25) } & & \\
\hline & No. & $\%$ & No. & $\%$ & & \\
\hline \multicolumn{7}{|l|}{ Smoking: } \\
\hline Yes & 13 & 52.0 & 15 & 60.0 & 0.32 & 0.57 \\
\hline No & 12 & 48.0 & 10 & 40.0 & & \\
\hline \multicolumn{7}{|l|}{ ICU Diagnosis } \\
\hline Trauma & 15 & 60.0 & 11 & 44.0 & 1.51 & 0.47 \\
\hline Medical & 6 & 24.0 & 7 & 28.0 & & \\
\hline Surgical & 4 & 16.0 & 7 & 28.0 & & \\
\hline \multicolumn{7}{|l|}{ Reasons of intubation } \\
\hline Major surgery & 2 & 8.0 & 4 & 16.0 & & \\
\hline Neurological problems & 11 & 44.0 & 9 & 36.0 & 1.84 & 0.93 \\
\hline Stroke & 4 & 16.0 & 3 & 12.0 & & \\
\hline Respiratory failure & 2 & 8.0 & 2 & 8.0 & & \\
\hline COPD & 1 & 4.0 & 1 & 4.0 & & \\
\hline Cardiac arrest & 2 & 8.0 & 1 & 4.0 & & \\
\hline Other(hypoxia) & 3 & 12.0 & 5 & 20.0 & & \\
\hline \multicolumn{7}{|l|}{ Duration on mechanical ventilation(days) } \\
\hline $7 \square$ & 9 & 36.0 & 7 & 28.0 & 0.36 & 0.54 \\
\hline \multirow{2}{*}{$\begin{array}{c}7< \\
\text { Range }\end{array}$} & 16 & 64.0 & 18 & 72.0 & & \\
\hline & \multicolumn{2}{|c|}{$6.9 \pm 10.1$} & $5.0-23.0$ & $8.2 \pm 9.3$ & $\begin{array}{l}\text { t-test } \\
0.47\end{array}$ & 0.64 \\
\hline
\end{tabular}

(*) statistically significant $<0.05$

- COPD: Chronic Obstructive Pulmonary Diseases.

Table (1) shows that more than half of the study and control groups were smokers $(52.0 \%, 60.0 \%$ respectively). In relation to ICU diagnosis, it was noted that the majority of patients in both groups were diagnosed as trauma, it represents $60 \%$ for the study group compared with $44 \%$ for the control group. Concerning the reasons of intubation, it was found that $44 \%$ of patients in study group were intubated due to neurological problems compared with $36 \%$ of patients in the control group followed by $16 \%$ due to stroke among study group and $20 \%$ of the patients in control group due to hypoxia. As regards the duration on mechanical ventilation, it was showed that more than half of the study group $64 \%$ were intubated for more than 7 days compared with $72 \%$ of the control group. Moreover, the mean day on mechanical ventilation was $(6.9 \pm 10.1)$ days in study group and (8.2 \pm 9.3$)$ days in control group. The differences between the two groups regarding clinical data characteristics were not statistically significance $(\mathrm{P}>0.05)$.

Table (2): Comparison of Beck oral health assessment among study and control groups on (Day1) of the study

\begin{tabular}{|c|c|c|c|c|c|c|}
\hline \multirow[t]{3}{*}{ Beck oral health assessment } & \multicolumn{4}{|c|}{ Groups } & \multirow{3}{*}{$\mathbf{X}^{2}$} & \multirow{3}{*}{ P-Value } \\
\hline & \multicolumn{2}{|c|}{ Study(n=25) } & \multicolumn{2}{|c|}{ Control(n=25) } & & \\
\hline & No. & $\%$ & No. & $\%$ & & \\
\hline \multicolumn{7}{|l|}{ Lips: } \\
\hline -Smooth, pink and intact. & 22 & 88.0 & 20 & 80.0 & 2.38 & 0.30 \\
\hline -Pale and slightly wrinkled. & 2 & 8.0 & 5 & 20.0 & & \\
\hline -Dry and slightly swollen. & 1 & 4.0 & $\mathbf{0}$ & 0.0 & & \\
\hline -Very dry and edematous. & $\mathbf{0}$ & 0.0 & $\mathbf{0}$ & 0.0 & & \\
\hline \multicolumn{7}{|l|}{ Gingival and oral mucosa: } \\
\hline -Smooth, pink and intact. & 24 & 96.0 & 21 & 84.0 & 2.20 & 0.33 \\
\hline -Pale and slightly wrinkled. & 1 & 4.0 & 3 & 12.0 & & \\
\hline -Dry and slightly swollen. & $\mathbf{0}$ & 0.0 & 1 & 4.0 & & \\
\hline -Very dry and edematous. & $\mathbf{0}$ & 0.0 & $\mathbf{0}$ & 0.0 & & \\
\hline \multicolumn{7}{|l|}{ Tongue: } \\
\hline -Smooth, pink and moist. & 22 & $\mathbf{8 8 . 0}$ & 23 & 92.0 & 0.22 & 0.64 \\
\hline -Pale and slightly wrinkled. & 3 & 12.0 & 2 & 8.0 & & \\
\hline -Dry and slightly swollen. & $\mathbf{0}$ & 0.0 & $\mathbf{0}$ & 0.0 & & \\
\hline -Very dry and edematous. & $\mathbf{0}$ & 0.0 & $\mathbf{0}$ & 0.0 & & \\
\hline \multicolumn{7}{|l|}{ Teeth: } \\
\hline -Clean and no debris. & 22 & 88.0 & 24 & 96.0 & 1.09 & 0.29 \\
\hline -Minimal debris. & 3 & 12.0 & 1 & 4.0 & & \\
\hline -Moderate debris. & $\mathbf{0}$ & 0.0 & $\mathbf{0}$ & 0.0 & & \\
\hline -Covered with debris. & $\mathbf{0}$ & 0.0 & $\mathbf{0}$ & 0.0 & & \\
\hline \multicolumn{7}{|l|}{ Saliva: } \\
\hline -Thin and watery plentiful. & 23 & 92.0 & 22 & 88.0 & 0.36 & 0.84 \\
\hline -Decrease in amount. & 1 & 4.0 & 2 & 8.0 & & \\
\hline -Scanty and slightly thicker. & 1 & 4.0 & 1 & 4.0 & & \\
\hline - Thick and viscid. & $\mathbf{0}$ & 0.0 & $\mathbf{0}$ & 0.0 & & \\
\hline
\end{tabular}

(*) statistically significant $<0.05$ 
Table (2) reveals that the majority of patients in the study group had smooth, pink, and intact lips, gingival and oral mucosa and tongue $(88.0 \%, 96.0 \%$, and $88.0 \%$, respectively) compared with $(80.0 \%, 84.0 \%$, and $92.0 \%$ ) of the control group. In addition, $88 \%$ of the study group had clean teeth and no debris compared with $96 \%$ of the control group. As regards saliva, it can be noted that the majority of both groups (study and control) had thin and watery plentiful saliva $(92.0 \%, 88.0 \%$, respectively). There were no statistically significant differences between the two groups regarding beck oral health assessment on day1.

Table (3): Comparison of Beck oral health assessment among study and control groups on (Day3) of the study

\begin{tabular}{|c|c|c|c|c|c|c|}
\hline \multirow[t]{3}{*}{ Beck oral health assessment } & \multicolumn{4}{|c|}{ Groups } & \multirow[t]{3}{*}{$\mathbf{X}^{2}$} & \multirow{3}{*}{ P-Value } \\
\hline & \multicolumn{2}{|c|}{ Study(n=25) } & \multicolumn{2}{|c|}{ Control(n=25) } & & \\
\hline & No. & $\%$ & No. & $\%$ & & \\
\hline Lips: & & & & & & \\
\hline -Smooth, pink and intact. & 21 & 84.0 & 18 & 72.0 & 1.52 & 0.47 \\
\hline -Pale and slightly wrinkled. & 2 & 8.0 & 5 & 20.0 & & \\
\hline -Dry and slightly swollen. & 2 & 8.0 & 2 & 8.0 & & \\
\hline -Very dry and edematous. & $\mathbf{0}$ & 0.0 & $\mathbf{0}$ & 0.0 & & \\
\hline Gingival and oral mucosa: & & & & & & \\
\hline -Smooth, pink and intact. & 23 & 92.0 & 14 & 56.0 & 8.65 & $0.03 *$ \\
\hline -Pale and slightly wrinkled. & 1 & 4.0 & 4 & 16.0 & & \\
\hline -Dry and slightly swollen. & 1 & 4.0 & 5 & 20.0 & & \\
\hline -Very dry and edematous. & $\mathbf{0}$ & 0.0 & 2 & 8.0 & & \\
\hline Tongue: & & & & & & \\
\hline -Smooth, pink and moist. & 21 & 84.0 & 12 & 48.0 & 8.25 & $0.04 *$ \\
\hline -Pale and slightly wrinkled. & 3 & 12.0 & 6 & 24.0 & & \\
\hline -Dry and slightly swollen. & 1 & 4.0 & 4 & 16.0 & & \\
\hline -Very dry and edematous. & $\mathbf{0}$ & 0.0 & 3 & 12.0 & & \\
\hline Teeth: & & & & & & \\
\hline -Clean and no debris. & 23 & 92.0 & 14 & 56.0 & 9.18 & $0.02 *$ \\
\hline -Minimal debris. & 2 & 8.0 & 6 & $\mathbf{2 4 . 0}$ & & \\
\hline -Moderate debris. & $\mathbf{0}$ & 0.0 & 3 & 12.0 & & \\
\hline -Covered with debris. & $\mathbf{0}$ & 0.0 & 2 & 8.0 & & \\
\hline Saliva: & & & & & & \\
\hline -Thin and watery plentiful. & 21 & 84.0 & 17 & 68.0 & 2.89 & 0.41 \\
\hline -Decrease in amount. & 3 & 12.0 & 4 & $\mathbf{1 6 . 0}$ & & \\
\hline -Scanty and slightly thicker. & 1 & 4.0 & 2 & 8.0 & & \\
\hline - Thick and viscid. & $\mathbf{0}$ & 0.0 & 2 & 8.0 & & \\
\hline
\end{tabular}

(*) statistically significant $<0.05$

Table (3) presents that $92 \%$ of patients in study group had smooth, pink and intact gingival and oral mucosa with clean teeth and no debris formation compared with $56 \%$ of patients in control group with statistically significant difference between the two groups, $(\mathrm{P}=0.03$ and 0.02 , respectively). Moreover, $12 \%$ of the control group had very dry and edematous tongue compared with no one of the study group, this difference was statistically significant $(\mathrm{P}=0.04)$. But no statistically significance was revealed among the two groups regarding lips and saliva $(\mathrm{P}=0.47$ and 0.41 , respectively).

Table (4): Comparison of Beck oral health assessment among study and control groups on (Day5) of the study

\begin{tabular}{|c|c|c|c|c|c|c|}
\hline \multirow[t]{3}{*}{ Beck oral health assessment } & \multicolumn{4}{|c|}{ Groups } & \multirow{3}{*}{$\mathbf{X}^{2}$} & \multirow{3}{*}{ P-Value } \\
\hline & \multicolumn{2}{|c|}{ Study(n=25) } & \multicolumn{2}{|c|}{ Control(n=25) } & & \\
\hline & No. & $\%$ & No. & $\%$ & & \\
\hline \multicolumn{7}{|l|}{ Lips: } \\
\hline -Smooth, pink and intact. & 20 & 80.0 & 11 & 44.0 & 7.05 & 0.1 \\
\hline -Pale and slightly wrinkled. & 2 & 8.0 & 7 & 28.0 & & \\
\hline -Dry and slightly swollen. & 2 & 8.0 & 4 & 16.0 & & \\
\hline -Very dry and edematous. & 1 & 4.0 & 3 & 12.0 & & \\
\hline \multicolumn{7}{|l|}{ Gingival and oral mucosa: } \\
\hline -Smooth, pink and intact. & 22 & 88.0 & 10 & 40.0 & 14.4 & $0.002 * *$ \\
\hline -Pale and slightly wrinkled. & 2 & 8.0 & 3 & 12.0 & & \\
\hline -Dry and slightly swollen. & 1 & 4.0 & 5 & 20.0 & & \\
\hline -Very dry and edematous. & $\mathbf{0}$ & 0.0 & 7 & 28.0 & & \\
\hline \multicolumn{7}{|l|}{ Tongue: } \\
\hline -Smooth, pink and moist. & 22 & $\mathbf{8 8 . 0}$ & 8 & 32.0 & 18.00 & $0.004 * *$ \\
\hline -Pale and slightly wrinkled. & 2 & 8.0 & 4 & 16.0 & & \\
\hline -Dry and slightly swollen. & 1 & 4.0 & 4 & 16.0 & & \\
\hline -Very dry and edematous. & $\mathbf{0}$ & 0.0 & 9 & 36.0 & & \\
\hline \multicolumn{7}{|l|}{ Teeth: } \\
\hline -Clean and no debris. & 24 & 96.0 & 7 & 28.0 & 24.9 & $<0.001 * *$ \\
\hline -Minimal debris. & 1 & 4.0 & 5 & 20.0 & & \\
\hline -Moderate debris. & $\mathbf{0}$ & 0.0 & 7 & 28.0 & & \\
\hline
\end{tabular}




\begin{tabular}{|l|c|c|c|c|c|c|}
\hline -Covered with debris. & 0 & 0.0 & 6 & 24.0 & & \\
\hline Saliva: & & & & & & \\
-Thin and watery plentiful. & 22 & 88.0 & 13 & 52.0 & 7.98 & $0.04^{*}$ \\
-Decrease in amount. & 1 & 4.0 & 5 & 20.0 & & \\
-Scanty and slightly thicker. & 1 & 4.0 & 2 & $\mathbf{8 . 0}$ & & \\
- Thick and viscid. & 1 & 4.0 & 5 & 20.0 & & \\
\hline
\end{tabular}

(*) statistically significant $<0.05$

Table (4) illustrates that $(28.0 \%, 36.0 \%$ and $24.0 \%)$ of patients in the control group had very dry and edematous of gingival and oral mucosa and tongue with teeth covered with debris compared with no one of patients in the study group with statistically significant difference between them $(\mathrm{P}=0.002,0.004$ and $<0.001$, respectively). As regards saliva, it can be observed that $20 \%$ of patients in the control group had thick and viscid saliva compared with only $4 \%$ of patients in the study group with statistically significant differences between the both groups $(\mathrm{P}=0.04)$. However, the table shows no statistically significant difference was revealed among the two groups regarding lips $(\mathrm{P}=0.1)$.

Table (5): Comparison of oral health status changes between the study and control groups throughout study period (Day1, 3 and 5).

\begin{tabular}{|c|c|c|c|c|c|c|}
\hline \multirow[t]{3}{*}{ Oral health status changes } & \multicolumn{4}{|c|}{ Groups } & \multirow[t]{3}{*}{$\mathbf{X}^{2}$} & \multirow{3}{*}{ P-Value } \\
\hline & \multicolumn{2}{|c|}{$\operatorname{Study}(n=25)$} & \multicolumn{2}{|c|}{ Control(n=25) } & & \\
\hline & No. & $\%$ & No. & $\%$ & & \\
\hline $\begin{array}{l}\text { Day 1: } \\
\text {-Normal (5 Scores). } \\
\text {-Mild dysfunction (6-10 Scores). } \\
\text {-Moderate dysfunction (11-15 Sores). } \\
\text {-Severe dysfunction (16-20 Scores). }\end{array}$ & $\begin{array}{c}23 \\
\mathbf{2} \\
\mathbf{0} \\
\mathbf{0} \\
\end{array}$ & $\begin{array}{c}92.0 \\
8.0 \\
0.0 \\
0.0 \\
\end{array}$ & $\begin{array}{c}22 \\
3 \\
0 \\
0 \\
\end{array}$ & $\begin{array}{c}88.0 \\
12.0 \\
0.0 \\
0.0 \\
\end{array}$ & 0.22 & 0.64 \\
\hline $\begin{array}{l}\text { Day 3: } \\
\text {-Normal (5 Scores). } \\
\text {-Mild dysfunction (6-10 Scores). } \\
\text {-Moderate dysfunction (11-15 Sores). } \\
\text {-Severe dysfunction (16-20 Scores). }\end{array}$ & $\begin{array}{c}22 \\
2 \\
1 \\
0 \\
\end{array}$ & $\begin{array}{c}88.0 \\
8.0 \\
4.0 \\
0.0 \\
\end{array}$ & $\begin{array}{c}15 \\
5 \\
3 \\
2 \\
\end{array}$ & $\begin{array}{c}60.0 \\
20.0 \\
12.0 \\
8.0 \\
\end{array}$ & 5.61 & 0.13 \\
\hline $\begin{array}{l}\text { Day 5: } \\
\text {-Normal (5 Scores). } \\
\text {-Mild dysfunction (6-10 Scores). } \\
\text {-Moderate dysfunction (11-15 Sores). } \\
\text {-Severe dysfunction (16-20 Scores). }\end{array}$ & $\begin{array}{c}22 \\
2 \\
1 \\
0 \\
\end{array}$ & $\begin{array}{c}88.0 \\
8.0 \\
4.0 \\
0.0 \\
\end{array}$ & $\begin{array}{c}10 \\
5 \\
4 \\
6\end{array}$ & $\begin{array}{l}40.0 \\
20.0 \\
16.0 \\
24.0\end{array}$ & 13.6 & $0.004 * *$ \\
\hline
\end{tabular}

(*) statistically significant $<0.05$

Table (5) shows that the majority of patients in both groups (study and control) had normal oral health status $(92.0 \%$ and $88.0 \%$, respectively) on the first day of the study with no statistically significant difference between them $(\mathrm{P}=0.64)$. However, at the third day, $8 \%$ of patients in the control group suffered from severe dysfunction of oral health compared with no one of patients in the study group, but this difference did not reach to be statistically significance $(\mathrm{P}=0.13)$. Regarding the fifth day of the study, it can be observed that $24 \%$ of patients in the control group suffered from severe dysfunction of oral health status compared with no one patients in the study group and the difference reached to be highly statistically significant $(\mathrm{P}=0.004)$.

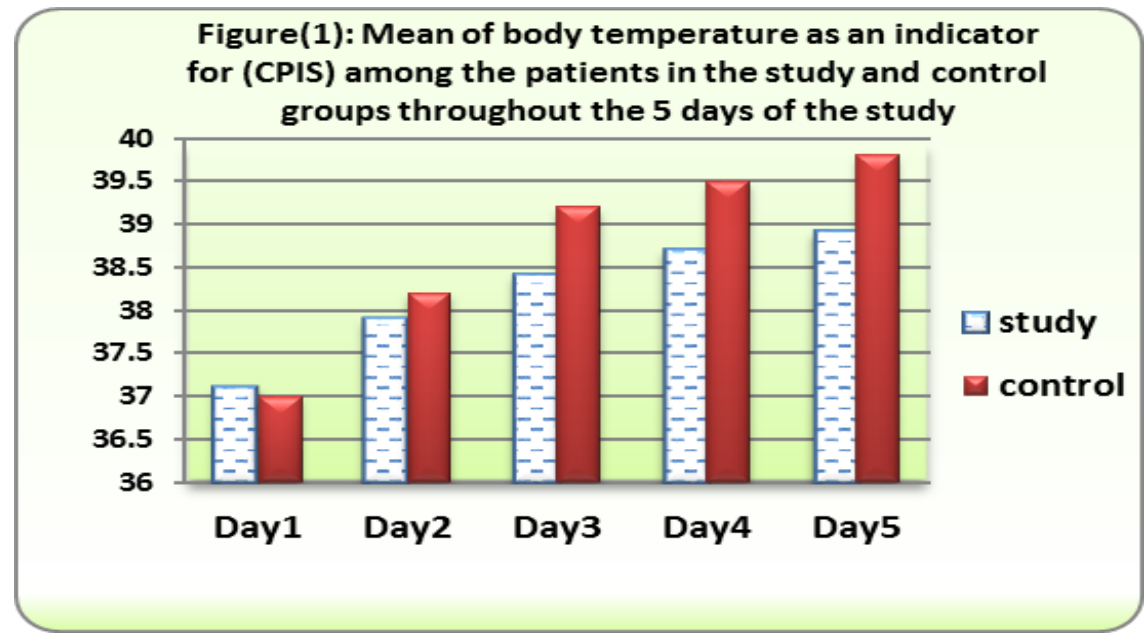


Figure (1) demonstrates that there were no statistically significant differences regarding to mean of body temperature on day1, 2, 3, 4, and 5 among study and control groups. It can be observed that on the $1^{\text {st }}$ day, the mean of body temperature was $37.1 \pm 0.2$ for the study group compared with $37.0 \pm 0.4$ for the control group. Meanwhile, at $5^{\text {th }}$ day, it was $38.9 \pm 0.5$ for the study group compared with $39.8 \pm 0.2$ for the control group.

Table (6): Comparison of White blood cell count (WBcs) follow up as an indicator for (CPIS) among the study and control groups throughout the 5 Days of the study

\begin{tabular}{|c|c|c|c|c|c|c|}
\hline \multirow{3}{*}{$\begin{array}{c}\text { WBes } \\
\text { Follow up }\end{array}$} & \multicolumn{4}{|c|}{ Groups } & \multirow{3}{*}{$\mathbf{X}^{2}$} & \multirow{3}{*}{ P-Value } \\
\hline & \multicolumn{2}{|c|}{$\operatorname{Study}(n=25)$} & \multicolumn{2}{|c|}{ Control(n=25) } & & \\
\hline & No. & $\%$ & No. & $\%$ & & \\
\hline $\begin{array}{l}\text { Day 1: } \\
-4 \text { to less than } 11 \times 1000 / \mu \mathrm{L} \text {. } \\
-11 \text { to less than } 14 \times 1000 / \mu \mathrm{L} \text {. } \\
-\square 14 \times 1000 / \mu \mathrm{L} .\end{array}$ & $\begin{array}{c}23 \\
2 \\
0\end{array}$ & $\begin{array}{c}92.0 \\
8.0 \\
0.0\end{array}$ & $\begin{array}{c}22 \\
\mathbf{3} \\
\mathbf{0}\end{array}$ & $\begin{array}{c}88.0 \\
12.0 \\
0.0\end{array}$ & 0.22 & 0.64 \\
\hline $\begin{array}{l}\text { Day 2: } \\
-4 \text { to less than } 11 \times 1000 / \mu \mathrm{L} \text {. } \\
-11 \text { to less than } 14 \times 1000 / \mu \mathrm{L} \text {. } \\
-\square 14 \times 1000 / \mu \mathrm{L} .\end{array}$ & $\begin{array}{c}21 \\
4 \\
0\end{array}$ & $\begin{array}{c}84.0 \\
16.0 \\
0.0 \\
\end{array}$ & $\begin{array}{c}20 \\
4 \\
1 \\
\end{array}$ & $\begin{array}{c}80.0 \\
16.0 \\
4.0 \\
\end{array}$ & 1.02 & 0.59 \\
\hline $\begin{array}{l}\text { Day 3: } \\
-4 \text { to less than } 11 \times 1000 / \mu \mathrm{L} \text {. } \\
-11 \text { to less than } 14 \times 1000 / \mu \mathrm{L} \text {. } \\
-\square 14 \times 1000 / \mu \mathrm{L} \text {. }\end{array}$ & $\begin{array}{c}21 \\
3 \\
1\end{array}$ & $\begin{array}{c}84.0 \\
12.0 \\
4.0\end{array}$ & $\begin{array}{c}19 \\
4 \\
2 \\
\end{array}$ & $\begin{array}{c}76.0 \\
16.0 \\
8.0\end{array}$ & 0.58 & 0.74 \\
\hline $\begin{array}{l}\text { Day } 4: \\
-4 \text { to less than } 11 \times 1000 / \mu \mathrm{L} \text {. } \\
-11 \text { to less than } 14 \times 1000 / \mu \mathrm{L} \text {. } \\
-\square 14 \times 1000 / \mu \mathrm{L} \text {. }\end{array}$ & $\begin{array}{c}20 \\
3 \\
2\end{array}$ & $\begin{array}{c}80.0 \\
12.0 \\
8.0\end{array}$ & $\begin{array}{c}14 \\
5 \\
6 \\
\end{array}$ & $\begin{array}{l}56.0 \\
20.0 \\
24.0 \\
\end{array}$ & 3.56 & 0.17 \\
\hline $\begin{array}{l}\text { Day 5: } \\
-4 \text { to less than } 11 \times 1000 / \mu \mathrm{L} \text {. } \\
-11 \text { to less than } 14 \times 1000 / \mu \mathrm{L} \text {. } \\
-\square 14 \times 1000 / \mu \mathrm{L} \text {. }\end{array}$ & $\begin{array}{c}20 \\
2 \\
3\end{array}$ & $\begin{array}{c}80.0 \\
8.0 \\
12.0\end{array}$ & $\begin{array}{c}11 \\
6 \\
8\end{array}$ & $\begin{array}{l}44.0 \\
24.0 \\
32.0\end{array}$ & 6.89 & $\mathbf{0 . 0 3} *$ \\
\hline
\end{tabular}

(*) statistically significant $<0.05$

Table (6) shows that there were no statistically significant differences revealed among the two groups (study and control) at $1^{\text {st }}, 2^{\text {nd }}, 3^{\text {rd }}$, and $4^{\text {th }}$ day of the study $(\mathrm{P}=0.64,0.59,0.74$ and 0.17 , respectively). However, at $5^{\text {th }}$ day, it was noted that $32 \%$ of patients in the control group had WBcs count $\geq 14 \times 1000 / \mu \mathrm{L}$. compared with $12 \%$ of patients in the study group with statistically significant difference between both groups $(\mathrm{P}=0.03)$.

Table (7): Comparison of sputum color follow up as an indicator for (CPIS) among the study and control groups throughout the 5 Days of the study

\begin{tabular}{|c|c|c|c|c|c|c|}
\hline \multirow{3}{*}{$\begin{array}{l}\text { Sputum color } \\
\text { follow up }\end{array}$} & \multicolumn{4}{|c|}{ Groups } & \multirow[t]{3}{*}{$\mathbf{X}^{2}$} & \multirow{3}{*}{ P-Value } \\
\hline & \multicolumn{2}{|c|}{$\operatorname{Study}(n=25)$} & \multicolumn{2}{|c|}{ Control(n=25) } & & \\
\hline & No. & $\%$ & No. & $\%$ & & \\
\hline $\begin{array}{l}\text { Day 1: } \\
\text {-White/ clear secretions. } \\
\text {-Sticky yellow secretions. } \\
\text { - Green secretions. }\end{array}$ & $\begin{array}{c}25 \\
\mathbf{0} \\
\mathbf{0}\end{array}$ & $\begin{array}{c}100.0 \\
0.0 \\
0.0\end{array}$ & $\begin{array}{c}24 \\
1 \\
0\end{array}$ & $\begin{array}{c}96.0 \\
4.0 \\
0.0\end{array}$ & 1.02 & 0.31 \\
\hline $\begin{array}{l}\text { Day 2: } \\
\text {-White/ clear secretions. } \\
\text {-Sticky yellow secretions. } \\
\text { - Green secretions. }\end{array}$ & $\begin{array}{c}25 \\
0 \\
0\end{array}$ & $\begin{array}{c}100.0 \\
0.0 \\
0.0\end{array}$ & $\begin{array}{c}23 \\
2 \\
0\end{array}$ & $\begin{array}{c}92.0 \\
8.0 \\
0.0\end{array}$ & 2.08 & 0.15 \\
\hline $\begin{array}{l}\text { Day 3: } \\
\text {-White/ clear secretions. } \\
\text {-Sticky yellow secretions. } \\
\text { - Green secretions. }\end{array}$ & $\begin{array}{c}24 \\
1 \\
0\end{array}$ & $\begin{array}{c}96.0 \\
4.0 \\
0.0 \\
\end{array}$ & $\begin{array}{c}19 \\
5 \\
1\end{array}$ & $\begin{array}{c}76.0 \\
20.0 \\
4.0 \\
\end{array}$ & 4.24 & 0.11 \\
\hline $\begin{array}{l}\text { Day 4: } \\
\text {-White/ clear secretions. } \\
\text {-Sticky yellow secretions. } \\
\text { - Green secretions. }\end{array}$ & $\begin{array}{c}22 \\
2 \\
1\end{array}$ & $\begin{array}{c}88.0 \\
8.0 \\
4.0\end{array}$ & $\begin{array}{c}16 \\
4 \\
5\end{array}$ & $\begin{array}{l}64.0 \\
16.0 \\
20.0\end{array}$ & 4.28 & 0.12 \\
\hline $\begin{array}{l}\text { Day 5: } \\
\text {-White/ clear secretions. } \\
\text {-Sticky yellow secretions. } \\
\text { - Green secretions. }\end{array}$ & $\begin{array}{c}20 \\
4 \\
1\end{array}$ & $\begin{array}{c}80.0 \\
16.0 \\
4.0 \\
\end{array}$ & $\begin{array}{c}11 \\
7 \\
7 \\
\end{array}$ & $\begin{array}{l}44.0 \\
28.0 \\
28.0\end{array}$ & 7.93 & $0.01 *$ \\
\hline
\end{tabular}

\section{(*) statistically significant $<0.05$}

Table (7) reveals that there were no statistically significant differences among the study and control groups at $1^{\text {st }}, 2^{\text {nd }}, 3^{\text {rd }}$, and $4^{\text {th }}$ day of the study regarding sputum color $(\mathrm{P}=0.31,0.15,0.11$ and 0.12 , respectively). However, at the $5^{\text {th }}$ day, $28 \%$ of the patients in control group suffered from sticky yellow and green secretions (for each) compared with the patients in study group (16.0\% and $4.0 \%$, respectively). With statistically significant difference between both groups $(\mathrm{P}=0.01)$. 


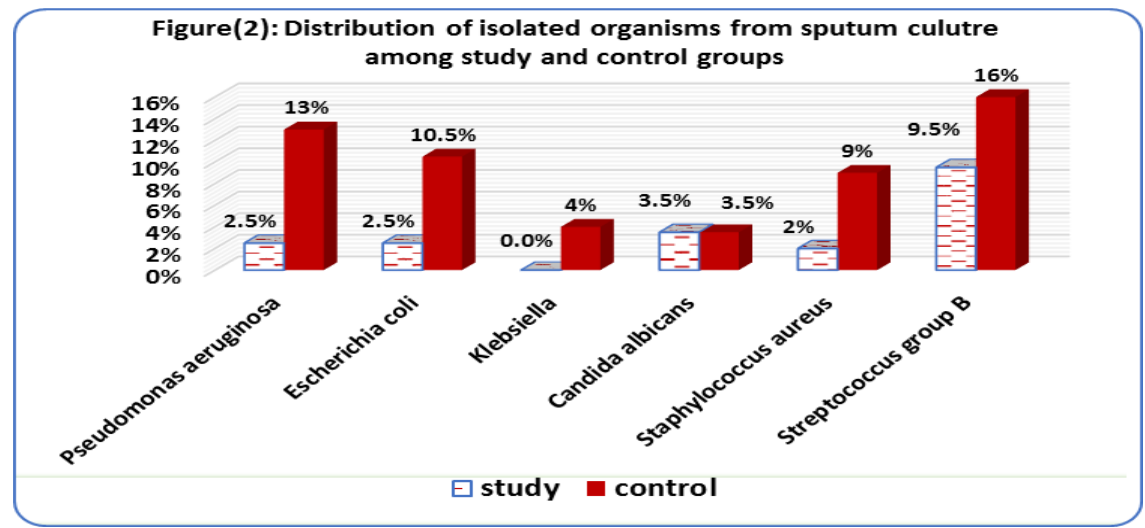

Figure (2) illustrates that the majority of an isolated organism among control and study groups, count (16.0\% VS 9.5\%, respectively) was streptococcus group B, followed by (13.0\% VS $2.5 \%$, respectively) of pseudomonas aeruginosa and (10.5\% VS $2.5 \%$ respectively) of Escherichia coli, then $(9.0 \%$ VS $2.0 \%$, respectively) of staphylococcus aureus and only $4 \%$ of klebsiella in control group with completely disappear in the study group. In addition, $3.5 \%$ of each group had candida. There were significant differences regarding the isolated organisms (pseudomonas aeruginosa, Escherichia coli, staphylococcus aureus and klebsiella) from sputum culture among study and control groups $(\mathrm{P}=0.03,0.01,0.02$ and 0.04 , respectively).

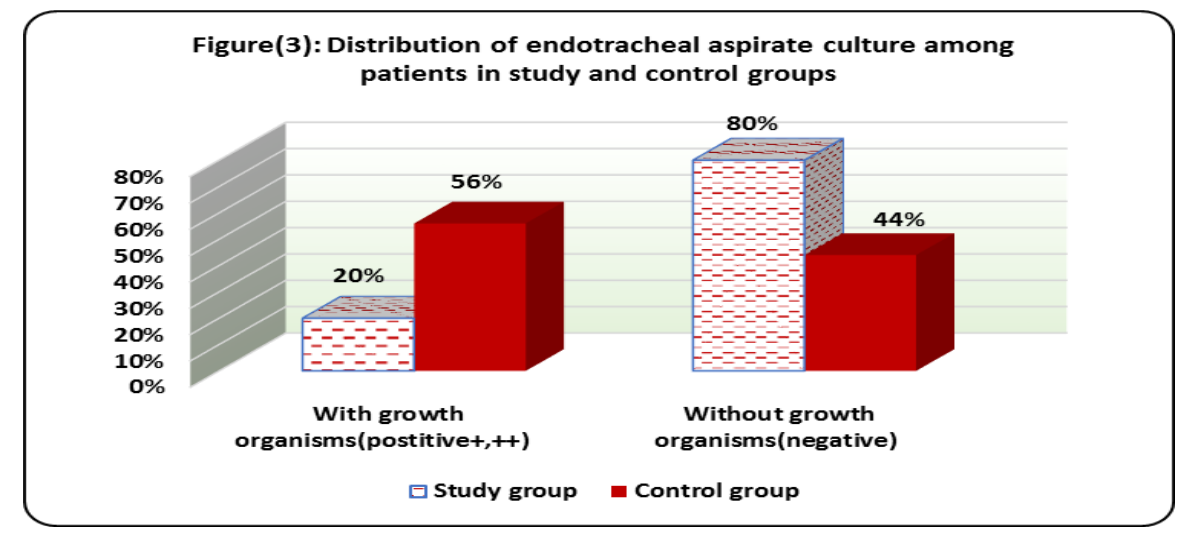

Figure (3) demonstrates that there was highly statistically significant difference regarding total positive $(+,++)$ sputum culture between the study and control groups $(\mathrm{P}<0.001)$.

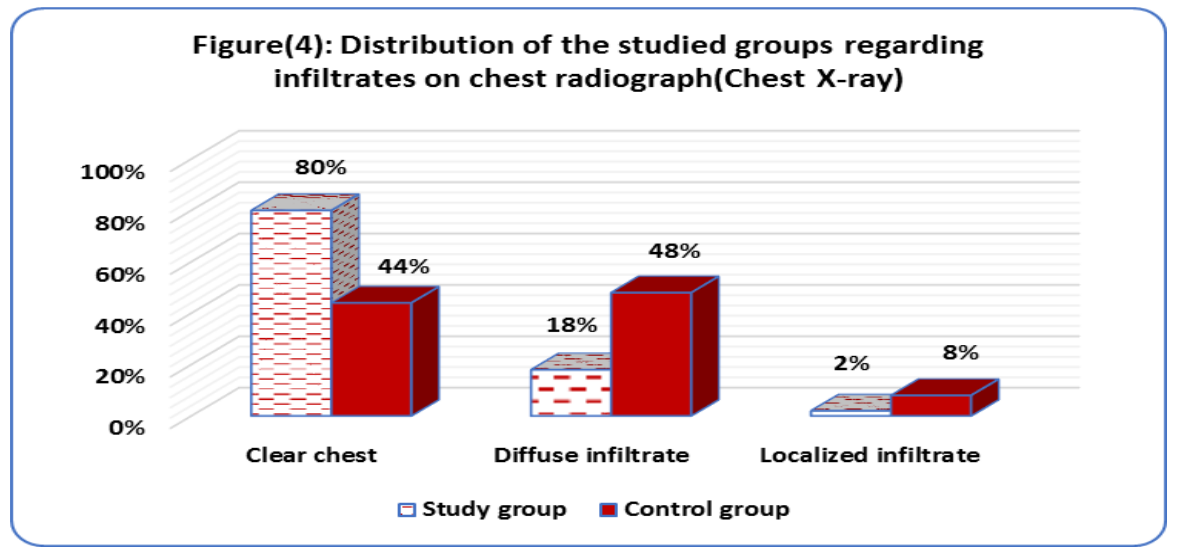

Figure (4) represents that $80 \%$ of the study group had clear chest compared with $44 \%$ of the control group, while $48 \%$ of patients in control group suffered from diffuse infiltrate compared with only $18 \%$ of patients in study group. There were statistically significant differences in chest $\mathrm{x}$-ray regarding clear chest and diffuse infiltrate between the study and control groups $(\mathrm{P}<0.01)$ for each. However, there is no significant differences between them regarding localized infiltrate chest $\mathrm{X}$-ray $(\mathrm{P}=0.05)$. 
Table (8): Frequency of ventilator-associated pneumonia (VAP) occurrence among patient in the study and control groups $(\mathrm{n}=50)$

\begin{tabular}{|c|c|c|c|c|c|c|}
\hline \multirow[t]{3}{*}{ Frequency of VAP occurrence } & \multicolumn{4}{|c|}{ Groups } & \multirow[t]{3}{*}{$\mathbf{X}^{2}$} & \multirow{3}{*}{ P-Value } \\
\hline & \multicolumn{2}{|c|}{ Study $(n=25)$} & \multicolumn{2}{|c|}{ Control(n=25) } & & \\
\hline & No. & $\%$ & No. & $\%$ & & \\
\hline -Diagnosis of VAP. & 5 & 20.0 & 14 & 56.0 & \multirow[b]{2}{*}{6.88} & \multirow[b]{2}{*}{ 0.009* } \\
\hline -Absence of VAP. & 20 & 80.0 & 11 & 44.0 & & \\
\hline
\end{tabular}

(*) statistically significant $<0.05$

Table (8) illustrates that $20 \%$ of patients in the study group was diagnosed of VAP compared with $56 \%$ of patients in the control group with highly statistically significant difference between them $(\mathrm{P}=0.009)$.

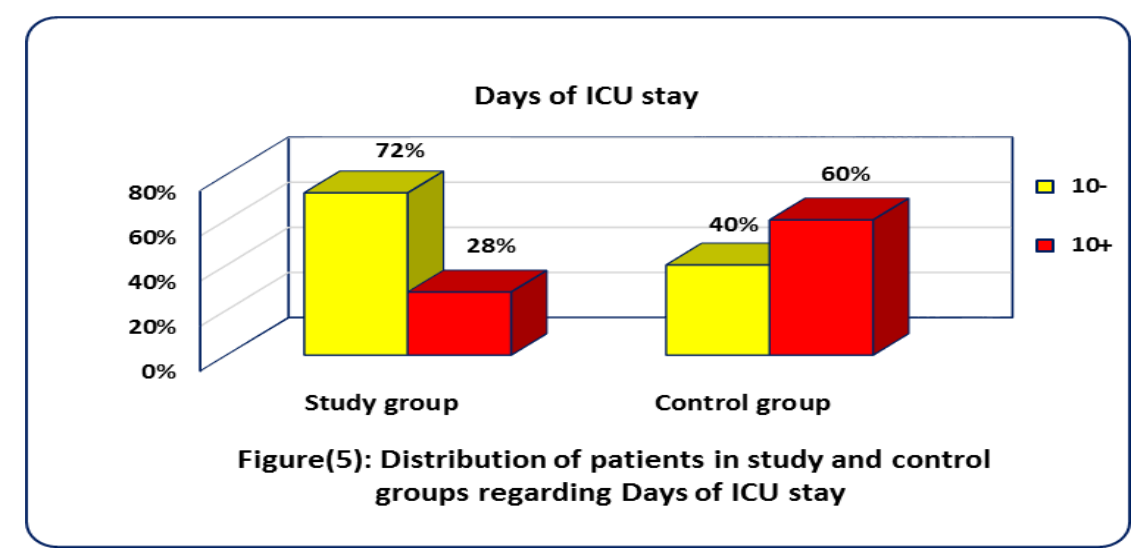

Figure (5) demonstrates that only $28 \%$ of patients in the study group stayed for more than 10 days in the ICU compared with $60 \%$ of patients in the control group with statistically significant difference between both groups as regards days of ICU stay $(\mathrm{P}=0.02)$.

\section{Discussion}

Oral care in critically ill adults is now emerging as an important issue. It is a standard part of the daily nursing care and is one method of lowering the incidence of VAP (Abd El-Aziz, 2014) ${ }^{(25)}$. Over the last two decades, there has been emerging evidence to demonstrate different techniques of oral care. Despite this evidence, there has been little advancement in the development of standardized oral hygiene protocols in ICU (Marino et al., 2015) ${ }^{(26)}$. As VAP continues to be a common complication of critical care, development of preventive approaches is essential to reduce the incidence of VAP (Sharma and Kaur 2012) ${ }^{(23)}$. The aim of this study was to examine the effect of chlorhexidine solution formula on oral health status and occurrence of ventilator - associated pneumonia among intubated intensive care unit patients. It was hypothesized that the intubated patients who will use chlorhexidine solution formula (study group) will be expected to improve oral health status and reduce occurrence of ventilator -associated pneumonia compared to (control group) patients who will not use this formula.

The results have shown that the study and control groups were homogeneous in respect to their age, sex, and all clinical data characteristics. This similarity in both groups was necessary to obviate any undesirable confounding effect of these variables on the outcomes of the study. This is in congruence with Caserta et al., (2012) ${ }^{(27)}$ who have reported that age, smoking habits as well as medical diagnosis on admission are known to be predictor factors for developing VAP. In the same line, Cook, (2004) ${ }^{(28)}$, identified that the duration of ventilation as an important determinant for the development of VAP.Concerning, comparison of beck oral health assessment among study and control groups on day1, revealed no statistically significant differences between them. This was also important to ensure comparability of the two groups, and confirm successful randomization.This support the idea of Snyders et al., (2011) ${ }^{(29)}$ that the antiseptic solution has no effect before three days of its use. In the same vein, Muscedere et al., $(2011)^{(30)}$ found that chlorhexidine solution formula should be used for more than 72 hours to get bacteriostatic effect and improve oral hygiene.

At the third day, the current study noted that the majority of patients in the study group had smooth, pink and intact gingival and oral mucosa with clean teeth and no debris formation compared with slightly more than half of patients in control group with statistically significant difference between the two groups, $(\mathrm{P}=0.03$ and 0.02 , respectively). Moreover, slightly more than one tenth of the control group had very dry and edematous tongue compared with no one of the study group, this difference was statistically significant $(\mathrm{P}=0.04)$. As the 
duration of intubation increased, the condition of the oral status became worse among the control group. Our results are in agreement with Coppadoro et al., (2012) ${ }^{(31)}$ who found that the use of chlorhexidine solution formula in critically ill patients improves their oral health hygiene and significantly reduces the incidence of debris accumulation, keep teeth clean and tongue moist with free from dryness. Moreover, in a study by Nasiriani et al.,(2016) ${ }^{(20)}$ who demonstrated that using a foam brush soaked in chlorhexidine reduces plaque and controls gingivitis.

At the fifth day, the end of oral care intervention, the current study revealed that the scores on items (gingival and oral mucosa, tongue, teeth and saliva) reflected worsening oral health among control group compared with the study group. As more than one quarter of patients in control group had very dry and edematous of gingival and oral mucosa and tongue compared with no one patients in study group. In addition, slightly less than one quarter of the control group had teeth covered with debris and thick saliva compared with no one patients in study group. This may be attributes to the fact that the study group follow chlorhexidine solution formula (chlorhexidine gluconate, peppermint, ethanol, glycerin) with using tooth brushing which improves the mouth hygiene for the patients and improve the oral environment that includes (gingival and oral mucosa, tongue, teeth and saliva) compares with control group who using swabbing of the mouth with normal saline $0.9 \%$ on tongue depressor wrapped in gauze. This finding is in agreement with Garcia et al., (2009) ${ }^{(32)}$ who have reported that tooth brushing has been demonstrated to be effective than cotton/gauze swabs in removing debris and plaque. In the same line Awad, (2007) ${ }^{(33)}$ revealed that normal saline group faced problems of oral health than chlorhexidine group and get best results in improving oral health status, removes debris, plaque and prevents gingival bleeding. Chan et al., (2011) ${ }^{(22)}$ added that although normal saline is cost effective, but such use has not been thoroughly tested. Normal saline has limited use as a mouth rinse due to its tendency to cause dryness and ineffectiveness in removing hardened mucus, debris or crusts from the mouth. In this respect, Rujipong et al., (2009) ${ }^{(34)}$ explained that chlorhexidine solution formula promoting and maintaining the oral health effectively because chlorhexidine inhibits secretion of enzymes involving the adherence of bacteria in oral cavity resulting in the reduction of dental plaque accumulation and gingivitis and gingival bleeding could be reduced consequently.

Concerning comparison of oral health status changes between the study and control groups throughout study period, the current study noted that there was no statistically significant difference on the $1^{\text {st }}$ and $3^{\text {rd }}$ day of the study among both groups. It could be observed that highly significant difference was elicit between the study and control groups on $5^{\text {th }}$ day. The present study showed that nearly one quarter of patients in control group suffered from severe dysfunction of oral health status compared with no one patients in study group. So, it can be said that oral care with use of chlorhexidine solution formula was the best solution that improve oral health status. This finding supported by Prendergast et al., (2009) ${ }^{(35)}$ who found that during intubation, total oral assessment grade scores increased from baseline to $12^{\text {th }}$ day. Regarding to modified clinical pulmonary infection sheet score (CPIS), the current study for body temperature, observed that there was no significant difference observed among patients in study and control groups on the first, second, third, fourth and fifth day. On the same line, Zilberberg and Shorr (2010) ${ }^{(36)}$ identified that, during assessment of VAP, temperature was $>38.50 \mathrm{C}$ or $<36.5$ 0C. The present study findings are in partial agreement with Snyders et al., (2011) ${ }^{(29)}$, who reported that presence of fever in critically ill patients that were not having pneumonia might be related to another body infection.This finding in the same line with Berry et al., (2011) ${ }^{(9)}$, who explained that when the patient on mechanical ventilation, fever may be caused by a drug reaction, extrapulmonary infection, blood transfusion, or extrapulmonary inflammation.

Concerning WBcs count as an indicator for (CPIS), there was highly significant difference revealed among patients in study and control groups only on the fifth day of the study. It was observed that nearly one third the patients in control group had WBcs $\geq 14 \times 1000 / \mu \mathrm{L}$. compared with only one tenth the patients in study group. Coppadoro et al., (2012) ${ }^{(31)}$ explained that patients on mechanical ventilator had raised in leukocytosis, this give a strong suspicion for ventilator-associated pneumonia (VAP). In addition, it has recently been noted that critically ill patients may have phagocytosis and behave as functionally immunosuppressed even prior to emergence of pneumonia (Afshari et al.,2012) ${ }^{(37)}$. This effect is attributed from third day of intubation while the patient on mechanical ventilator which increase neutrophil phagocytic activity and phagocytosis by neutrophils (Rocha et al., 2013) ${ }^{(38)}$. Comparison of sputum color follow up as an indicator for(CPIS) results revealed that statistically significant differences between the two groups regarding sputum color only in the fifth day of the study. It was found that more than one half of the control group had sticky yellow and green secretions compared with less than one quarter of study group, which could explain the hindering effect of oral care intervention on patient outcome. (Rocha et al., 2013) ${ }^{(38)}$ who stated that the sputum sample is checked for blood as well as color and consistency. If the sputum is green, sticky yellow or brown it reflects the existence of an 
infection. However, Conway et al., $(2013)^{\left({ }^{(3)}\right)}$ described that the culture was positive if any of the following organisms were cultured: Staphylococcus aureus, Streptococcus pneumoniae, Haemophilus influenzas, Moraxella catarrhalis, Klebsiella pneumonia, Serratia marcescens, Proteus mirabilir, Escherichia coli, Enterobacter cloacae, or Pseudomonas aeruginosa.

As regards to the types of bacterial species isolated by endotracheal aspirates from both study and control groups, it can be noted that the most frequent isolated microorganisms were Gram positive bacteria such as Streptococcus pneumoniae and Staphylococcus aureus and Gram negative bacteria as Pseudomonas aeruginosa, Escherichia coli and Klebsiella pneumonia were isolated in considerable percentage. In agreement with the current study, Afshari et al., (2012) ${ }^{(37)}$ found that Gram positive bacteria including Streptococcus pneumoniae and Staphylococcus aureus were isolated from the tracheal secretions within first 48 hours of intubation. The current study findings are in partial agreement with El-Kousy (2001) ${ }^{(40)}$, who studied the surveillance of pseudomonas aeruginosa and Klebsiella in Critical Care Unit of Alexandria Main University Hospital. The study showed that the main types of organisms isolated from the tracheal secretions were Klebsiella species, Pseudomonas aeruginosa followed by Staphylococcus aureus. Isolation of organisms from tracheal secretions in the current study may be attributed to the presence of several routes by which microorganisms enter the lower airway in an intubated patient.

In the present study, there was highly statistically significant difference regarding total positive $(+,++)$ sputum culture between the study and control groups. The current study revealed that slightly more the one half of patients in control group had positive growth organisms compared with only less than one quarter of patients in study group. In the same line, Fathy et al., (2013) ${ }^{(4)}$ explained that, the poor dental hygiene has been linked to respiratory pathogen colonization in residents of long-term care facilities, and dental plaque may serve as the reservoir for these virulent pathogens, especially in high-risk patients with poor oral hygiene.Moreover, Prendergast et al., (2012) ${ }^{(11)}$ who reported that bacterial colonization of the oropharynx occurred in the majority of patients and organisms isolated from the mouth before diagnosis of pneumonia were identical to the pathogen that cause pneumonia.The current study revealed that the majority of study group had clear chest compared with only less than one half of control group. In addition, slightly less than one half of patients in control group had diffuse infiltrate on chest-x ray at the end of oral care intervention $\left(5^{\text {th }}\right.$ day) compared with more than one tenth of patients in study group. The improvement of oral health status among the study group compared with the control group, reflects results of chest x-ray which is the best test for diagnosing pneumonia. Rocha et al., (2013) ${ }^{(38)}$ assured that chest radiography with postero-anterior and lateral views is the preferred imaging examination for the evaluation of typical bacterial pneumonia. The study findings were in agreement with Sharma and Kaur (2012) ${ }^{(23)}$ who reported that in most patients, radiographs demonstrate a patchy bronchopneumonic pattern, but segmental and lobar infiltration may be seen. In the same vein, Nasiriani et al., (2016) ${ }^{(20)}$ reported that when patients present with fever, leukocytosis, or cough, pneumonia is suggested based on focal or diffuse opacities.

The major finding of this study was that the application of chlorhexidine solution formula on mechanically ventilated patients reduced significantly the occurrence of VAP when compared with routine hospital oral care. The incidence of VAP is highly statistically significant among the control group compared with the study group (56\% and $20 \%$ respectively). This can be attributes to the fact that application of chlorhexidine solution formula provided for the study group was effective in reducing VAP. These findings are in agreement with several organizations, including the CDC, $(2004){ }^{(8)}$ and APIC $(2007){ }^{(41)}$ that developed evidence based patient-care treatment practices and published best practices examples for reducing the occurrence of VAP. All of them stated that comprehensive oral hygiene has consistently been recognized as critical for the prevention of pneumonia in the hospitalized patients. In the same vein, Awad, (2007) ${ }^{(33)}$ emphasized that the protocol of oral care used reduce incidence of VAP among mechanically ventilated patients than the hospital routine mouth care and had a good effect in reducing bacterial load through removal of plaque, mucous, and bacteria from the mouth and teeth. Zilberberg and Shorr, $(2010)^{(36)}$ added that oral care with using $0.12 \%$ chlorhexidine gluconate with 15 -mL oral rinse for orally intubated patients is effective in improving oral health status and in reducing the ventilator associated pneumonia.Beside the main objective of the study, the current study illustrates that there was a statistical significant difference between study and control groups regarding days of ICU stay. The study revealed that slightly more than one quarter of patients in the study group stayed for more than 10 days in ICU compared with more than half of the control group. This finding goes hand in hand with Caserta et al., (2012) ${ }^{(27)}$ who reported that VAP prolongs ICU length of stay. In addition, Coppadoro et al., $(2012)^{(31)}$ reported that the mean days for ICU length of stay in patients with VAP was 11 days. On the other hand, the current study was in contrast with Ames et al., (2011) ${ }^{(f)}$ who found no significant difference in the length of stay for patients treated with chlorhexidine versus control group. 


\section{Conclusion}

Based on the present study results, it can be concluded that oral health status deteriorated in control group who used routine hospital care at 3rd day regarding gingival and oral mucosa, teeth and saliva compared with study group who used chlorhexidine solution formula and extends to the 5th day, the end of the study. This reflects effects of chlorhexidine solution formula in improving oral health status through keeping gingival, oral mucosa and tongue to be smooth, pink and intact; allow cleaning teeth with no debris and watery plentiful saliva. Moreover, it reduces growth of different bacterial species (Gram negative and positive bacteria) and in turn it has reducing the occurrence of ventilator associated pneumonia and thus, it shorts the length of stay in ICU which is consider an important determinant for the development of VAP.

\section{Recommendations For Practice And Research}

Based on the results of the current study, the following suggestions are recommended:

1. The use of chlorhexidine solution formula as an oral mouth care is recommended for orally intubated patients.

2. Apply of an oral health assessment tool is recommended for the immediate identification of oral problems for every patient.

3. Replication of the study using a large probability samples acquired from different geographic areas.

4. Develop written protocol oral care to be applying in the ICU.

5. An educational program should be established for nurses caring for mechanically ventilated patients in ICUs regarding comprehensive oral care.

6. Regular update about evidence based guidelines for oral care and its effect on VAP prevention.

\section{References}

[1]. Samuelson K.A. Adult intensive care patients' perception of endotracheal tube-related discomforts: a prospective evaluation. Heart Lung, (2011) 40: 49-55.

[2]. Grap M.J., Munro C.L. Preventing ventilator-associated pneumonia: evidence-based care. Critical Care Nursing Clinics of North America. (2004); 16: 349-358.

[3]. Berry A., Davidson P., Masters J. Patients receiving mechanical ventilation systematic literature review of oral hygiene practices for intensive care. Am J Crit Care (2007) 16: 552-562.

[4]. Fathy A., Abdelhafeez R., Abd Elhafez S., Elhafez S.A.A. Analysis of ventilator associated pneumonia (VAP) studies in Egyptian University Hospitals, Egyptian Journal of Chest Diseases and Tuberculosis (2013) 62: 17-25.

[5]. Seweilam N. Ventilator associated pneumonia in Mansoura university hospitals: incidence, risk factors and control, M.Sc. Thesis in Microbiology, Faculty of Medicine, Mansoura University (2003).

[6]. Munro, C.L., \& Grap, M.J. Oral health and care in the intensive care unit: state of the science, Am J Crit Care (2009), vol.13, no.1, P. 25-33.

[7]. Ames, J.N., Sulima,P., Yates, M.J., \& McCullagh, L.,et al. Effects of Systematic Oral Care in Critically Ill Patients: A Multicenter Study, AJCC, American journal of critical care (2011), Vol. 20, No. 5, P.103-114.

[8]. Center for Disease Control. Guidelines for preventing health care associated pneumonia, Recommendation of CDC and the health care infection control practices Advisory Committee. Morbidity and Mortality weekly report Recommendations and Report, (2004), 53(RR-3). 8

[9]. Berry A.M., Davidson P.M., NicholsonL, et al. consensus based clinical guideline for oral hygiene in the critically ill, Intensive. crit care Nurs (2011), 27,190-185.

[10]. Lorente, L., Blot, S. \& Rello, J. Evidence on measures for the prevention of ventilator-associated pneumonia, Eur Respir J (2007), vol. 30: no 6, P. 1193-1207.

[11]. Prendergast, V., Jakobsson, U., Renvert, S., \& Hallberg, R. I. Effects of a Standard Versus Comprehensive Oral Care Protocol Among Intubated Neuroscience ICU Patients: Results of a Randomized Controlled Trial, Journal of Neuroscience Nursing (2012), Vol.44, No.3, P.134 - 146.

[12]. Genuit T., Bochicchio G., Napolitano L.M., McCarter R.J., Roghman M.C. Prophylactic chlorhexidine oral rinse decreases ventilatorassociated pneumonia in surgical ICU patients. Surg Infect (Lancet) (2001), 2:5-18

[13]. Houston S., Hougland P., Anderson J.J., LaRocco M., Kennedy V., Gentry L.O. Effectiveness of $0.12 \%$ chlorhexidine gluconate oral rinse in reducing prevalence of nosocomial pneumonia in patients undergoing heart surgery. Am J Crit Care (2002), 11:567-570.

[14]. Koeman M., Ven A.J., Hak E., Joore H.C., Kaasjager K., de Smet A.G., Ramsay G., Dormans T.P., Aarts L.P., de Bel E.E., Hustinx W.N., Tweel I., Hoepelman A.M., Bonten M.J. Oral decontamination with chlorhexidine reduces the incidence of ventilator-associated pneumonia. Am J Respir Crit Care Med (2006), 173(12):13481355.

[15]. Lansford T., Moncure M., Carlton E. Endress R., Shik N., Udobi K., Braxton C., Danks R. Efficacy of a pneumonia prevention protocol in the reduction of ventilator-associated pneumonia in trauma patients. Surgical Infections (2007), 8:505-510

[16]. Mori H., Hirasawa H., Oda S., Shiga H., Matsuda K., Nakamura M. Oral care reduces incidence of ventilator-associated pneumonia in ICU populations. Intensive Care Med (2006), 32:230-236.

[17]. Garland, J. S. Strategies to prevent ventilator-associated pneumonia in neonates. Clin Perinatol, (2010), 37(3), pp. 629-643

[18]. Fishbein, M., \& Ajzen, I. Predicting and changing behavior: A reasoned action, approach. New York, psychology: Taylor and Francis Group (2010).

[19]. Beck S. Impact of a systemic oral care protocol on stomatitis after chemotherapy. Cancer Nurs. (1997);2(3):185-199.

[20]. Nasiriani K., Torki F., Jarahzadeh M.H., Maybodi F.R. The effect of brushing with a soft toothbrush and distilled water on the incidence of ventilator-associated pneumonia in the intensive care unit. National research institute of tuberculosis and lung disease, Iran (2016); 15(2): 101-107. 
[21]. The American Thoracic Society and the Infectious Diseases Society of America. Guidelines for the management of adults with hospital-acquired, Ventilator-Associated Pneumonia. Am J Repir Crit Care Med (2005); 171:388-416.

[22]. Chan E.Y., Lee Y.K., Poh T.H., Ng I.H., Prabhakaran L. Translating evidence into nursing practice: oral hygiene for care dependent adults. Int J Evid Based Healthcare (2011) 9: 172-183.

[23]. Sharma S.K. and Kaur J. Randomized control trial on efficacy of chlorhexidine mouth care in prevention of ventilator-associated pneumonia (VAP). Nursing and Midwifery Research Journal (2012); Vol-8, No.2:169-178.

[24]. Fartoukh M., Maitre B., Honore S., Cerf C., Zahar J.R., Brun C. Diagnosing pneumonia during mechanical ventilation: the clinical pulmonary infection score revisited. Am J Respir Crit Care Med. (2003); 168(2): 173-179.

[25]. Abd El-Aziz M.A. Effect of educational program on nurses, knowledge and skills about oral care for traumatized patients, AlAzhar Assiut Medical Journal (2014), Vol (12), No (1):25-47

[26]. Marino P.J., Hannigan A., Haywood S., Cole J.M., Palmer N., Emanuel C., Lewis M., Wise M.P., and Williams D.W. Comparison of foam swabs and toothbrushes as oral hygiene interventions in mechanically ventilated patients: a randomized split mouth study, BMJ (2015), Vol.2 No.1:9-14.

[27]. Caserta R.A., Marra A.R., Durão M.S., Silva C.V., dos Santos O.F.P, et al. A program for sustained improvement in preventing ventilator associated pneumonia in an intensive care setting. BMC Infectious Diseases (2012) 12: 234235.

[28]. Cook D. Ventilator associated pneumonia: perspectives on the burden of illness. Intensive Care Medicine (2004), 26 (11): $531-537$.

[29]. 29]. Snyders O., Khondowe O., Bell J. Oral chlorhexidine in the prevention of ventilator associated pneumonia in critically ill adults in the ICU: A systematic review (2011). SAJCC 27: 48-56.

[30]. Muscedere J., Rewa O., McKechnie K., Jiang X., Laporta D., et al. Subglottic secretion drainage for the prevention of ventilator-associated pneumonia: a systematic review and meta-analysis. Crit Care Med (2011) 39: 1985-1991.

[31]. Coppadoro A., Bittner E., Berra L. Novel preventive strategies for ventilator-associated pneumonia. Crit Care (2012) 16: 210.

[32]. Garcia R., Jendresky L., Colbert L., Bailey A., Zaman M., et al. Reducing ventilator-associated pneumonia through advanced oral-dental care: a 48-month study. Am J Crit Care (2009) 18: 523-532.

[33]. Awad S.H. Effect of a nursing intervention on oral health status of orally intubated patients, MSc thesis, Faculty of Nursing, University of Alexandria. Egypt (2007).

[34]. Rujipong P., Lekutai S., Pinyopasakul W., and Rungruanghiranya S. The effect of using an oral care clinical nursing practice guideline on oral hygiene status and Ventilator-Associated Pneumonia in intubated patients, Journal of Nursing Science (2009), Vol.27, No.3:57-63.

[35]. Prendergast V., Hallberg.I. R., Jahnke R.N., Hage I.P. and Kleiman C. Oral Health, Ventilator-Associated Pneumonia, and Intracranial Pressure in Intubated Patients in a Neuroscience Intensive Care Unit Journal of the American Association of CriticalCare Nurses (2009), 18: 468-376.

[36]. Zilberberg M., and Shorr A.F. Ventilator -Associated Pneumonia: the clinical pulmonary infection score as a surrogate for diagnostics and outcome, Clinical Infectious Diseases. (2010), 51(S1): S131-S135.

[37]. Afshari A., Pagani L., Harbarth S. Year in review 2011: Critical care - infection. Crit Care 2012, 16: 242-247.

[38]. Rocha L.A., Marques Ribas R., da Costa Darini A.L., Gontijo Filho P.P. Relationship between nasal colonization and ventilator-associated pneumonia and the role of the environment in transmission of Staphylococcus aureus in intensive care units. Am J infect Control 2013, 41: 1236-1240.

[39]. Conway Morris A., Anderson N., Brittan M., Wilkinson T.S., McAuley D.F., Antonelli J., McCulloch C., Barr L.C., Dhaliwal K., Jones R.O., Haslett C., Hay A.W., Swann D.G., Laurenson I.F., Davidson D.J., Rossi A.G., Walsh T.S., Simpson A.J. Combined dysfunctions of immune cells predict nosocomial infection in critically ill patients. Br J Anaesth 2013, 3: 1-10

[40]. 40]. El- Kousy I. surveillance of Pseudomonas aeruginosa and klebsiella in critical care unit of Alexandria Main University Hospital. Unpublished Master thesis. Faculty of Nursing Alexandria University (2001).

[41]. APIC (2007). Preventing Ventilator Associated Pneumonia. Infection Control Week Brochure 8: 1. 